\title{
Al rescate de la niñez indígena. Reflexiones antropológicas a partir de una campaña de UNICEF Argentina
}

\author{
Andrea SzULC \\ CONICET-UBA \\ andrea.szulc@gmail.com
}

\author{
María Adelaida Colangelo \\ FTS- UNLP \\ adecolangelo@yahoo.com.ar
}

\author{
Paula SHABEL \\ CONICET- UBA \\ paulashabel@gmail.com
}

\author{
María Pía LEAVY \\ ICA-UBA-CONICET \\ pialeavy@gmail.com
}

Noelia ENRIZ

CONICET-UBA

noelia.enriz@gmail.com

\author{
María Celeste HernándeZ \\ LECyS-FTS- UNLP \\ mcelestehernandez@gmail.com
}

Recibido: 28-10-2014

Aceptado: 11-01-2016

\section{Resumen}

En este trabajo abordaremos, desde una perspectiva antropológica, la "campaña por los derechos de la niñez y la adolescencia indígena" lanzada por UNICEF Argentina en 2009, con el fin de problematizar las construcciones de niñez, de la cuestión indígena y de la noción de "derechos" que allí se ponen en juego. Distanciándonos de concepciones ontológicas sobre los derechos humanos, analizaremos esta campaña en tanto dispositivo cuyo efecto es la construcción de los niños indígenas como sujetos de derechos de maneras específicas. Para ello, indagamos en el modo en que fue ésta elaborada, así como en sus contenidos, procurando explicar qué derechos y qué representaciones de los niños indígenas se visibilizaron a través de ella y las tensiones suscitadas en su proceso de armado y presentación.

Palabras clave: Derechos humanos; niñez; pueblos indígenas; organismos internacionales.

\section{To the Rescue of Indigenous Children. Anthropological Reflections Stemming from a UNICEF Campaign in Argentina}

\begin{abstract}
This article presents an anthropological approach to the "Campaign for the Indigenous Children and Adolescents' Rights" launched by UNICEF Argentina in September 2009, with the purpose of analyzing the social constructions of childhood, of indigenous issues and the meanings of "rights" that are there implied. Far from human rights' ontological perspectives, we address this Campaign as a mechanism that constructs the idea of indigenous children as subjects of rights in specific ways. For this purpose, we examine the making process of the Campaign and its contents, attempting to clarify the precise rights and
\end{abstract}


representations of indigenous children claimed therein, as well as the tensions emerged in the producing and presenting process.

Key words: human rights; childhood; indigenous peoples; international organizations.

Referencia normalizada

Szulc, A. et al. (2016): “Al rescate de la niñez indígena”, Política y Sociedad, 53 (1), pp. 123-142.

Sumario: Introducción. 1. La campaña. 2. Exotismo, proyección al pasado y participación indígena. 3. A modo de cierre. 4. Bibliografía.

\section{Introducción}

En septiembre de 2009, UNICEF Argentina lanzó la "campaña por los derechos de la niñez y la adolescencia indígena", destinada tanto a hacer visibles "las vulneraciones específicas de derechos que sufre esta población en Argentina" como a "sensibilizar y lograr la movilización ciudadana" (UNICEF, 2009). ${ }^{1}$ Dado que la niñez indígena en Argentina continúa marcada por la escasa visibilidad, la pobreza, la exclusión y la violencia, consideramos valioso que UNICEF Argentina haya desarrollado tal iniciativa. Sin embargo, como antropólogas que desde hace años trabajamos con niños ${ }^{2}$ indígenas en diversos contextos del país, no podemos dejar de formularnos interrogantes acerca de cómo fueron representados tales niños, sus problemáticas y sus derechos en estos materiales audiovisuales y el modo en que fue producida tal campaña- interrogantes que ameritan un análisis antropológico. No es nuestro cometido señalar aciertos y desaciertos de la campaña, ni analizar su impacto o su estrategia comunicacional como tal, sino tomarla como vía para avanzar en la problematización de las construcciones de niñez, de la cuestión indígena y de la noción de "derechos" que se ponen en juego en el ámbito de los organismos de defensa de los derechos del niño, teniendo en cuenta que UNICEF constituye el uno de los actores centrales en él.

${ }^{1}$ UNICEF (Fondo de las Naciones Unidas para la Infancia), organismo intergubernamental surgido en 1946, en el contexto de la segunda Posguerra, estableció su sede en Argentina en 1985, en un marco en el que comenzaba a instalarse el debate público acerca de los derechos de los niños, que cristalizaría una década después en la adhesión a la Convención Internacional de los Derechos del Niño.

${ }^{2}$ Vale aclarar que frecuentemente utilizamos en este artículo el término "niños" como conjunto que abarca tanto a varones como mujeres, a pesar de conocer y acordar con que este uso -por el cual en castellano el término en masculino abarca y subsume al femenino- "no es ingenuo ni casual", como bien señala Eva Giverti (1998: 6). Se trata no obstante del uso corriente en nuestra lengua que resulta más práctico que especificar en cada oportunidad que hablamos de "niños y niñas" o "niños/ as" o "niñ@s", lo cual a nuestro entender sería además inadecuado, pues como ya hemos advertido (Szulc, 2007; Szulc, 2015) no siempre la variable de género requiere un primer plano. 
Indagaremos entonces, desde una perspectiva antropológica, en el modo en que la campaña fue elaborada, así como en sus contenidos, procurando explicar qué derechos y qué representaciones de los niños indígenas se visibilizaron a través de ella, así como las tensiones que a partir de ello se generaron. Pues, las declaraciones de derechos humanos -entre ellas las referidas a Derechos del Niño- al constituirse como "textos abstractos" (Godelier, 1998), pueden ser utilizadas en distintos contextos con diversas interpretaciones, abriendo un campo de negociaciones y disputas que requiere de un abordaje extra- legal (Messer, 1993). Esto implica considerar "los sentidos y significados que son construidos en contextos particulares, en la materialidad de las experiencias de los agentes que constituyen la realidad social en sus múltiples dimensiones" (Schuch, 2009:15, traducción propia). Compartimos con esta última autora una mirada sobre los derechos humanos que, alejándose de una concepción ontológica, los aborda desde los significados, usos, producciones y apropiaciones en sus formas concretas, situadas histórica y contextualmente.

Procuramos así ampliar las discusiones en curso para realizar un abordaje de los derechos en su dimensión cotidiana. En este caso, tomamos como objeto de análisis la campaña mencionada, entendida como un dispositivo que tiene como efecto la construcción de los niños indígenas como sujetos de derechos de maneras particulares, poniendo en tensión construcciones de la niñez y de la problemática indígena diversas, así como también formulaciones universalistas y derechos específicos reconocidos a los pueblos indígenas.

La metodología utilizada combina el relevamiento y análisis de los materiales de la campaña-gráficos y audiovisuales- con materiales etnográficos originales elaborados mediante observación participante y entrevistas etnográficas con algunos de los sujetos involucrados, con el fin de analizar las representaciones que se produjeron en este marco. La selección de tales sujetos se realizó mediante la estrategia que expertos en metodología cualitativa (Taylor y Bogdan, 1998; Guber, 2005) han denominado metafóricamente "bola de nieve". Este técnica implica "conocer a algunos informantes y lograr que ellos nos presenten a otros" (Bogdan y Taylor, 1998: 109), creando a partir de nuestros contactos preexistentes circuitos cada vez más abarcativos de entrevistados (Guber, 2005). Los planteos de los responsables de UNICEF y de los referentes indígenas fueron registrados y analizados además en el acto de lanzamiento de la campaña, el cual podemos caracterizar como "drama social", como lo definió Víctor Turner, en tanto episodio público de tensión que irrumpe en el proceso social, y que ilumina procesos implícitos hasta entonces, permitiendo descubrir dimensiones sociológicas, simbólicas y políticas de una problemática (Turner, 1974). A modo de contrapunto comparativo, utilizamos también materiales referentes a otras iniciativas de UNICEF, en tanto contribuyen a iluminar aspectos significativos del tema que aquí nos ocupa. ${ }^{3}$

${ }^{3}$ El trabajo etnográfico sobre la campaña aquí analizada fue realizado por Andrea Szulc, mientras que en el caso de otras campañas estuvo a cargo de María Pía Leavy. 
Como puntapié inicial, entonces, en la siguiente sección describimos brevemente las piezas audiovisuales y gráficas que integran la campaña, a modo de disparador del análisis antropológico que presentaremos en las secciones subsiguientes.

\section{La campaña}

Las campañas constituyen un tipo de estrategia de comunicación que UNICEF pone en práctica para sensibilizar y movilizar acerca de temas que son definidos como prioritarios (UNICEF, s/f). En el caso particular aquí analizado, la "campaña por los derechos de la niñez y la adolescencia indígena" se enmarcó en un llamamiento de UNICEF a tomar medidas para visibilizar la vulnerabilidad de las comunidades indígenas en Argentina, específicamente de sus niños y adolescentes, que sufren obstáculos para acceder a los servicios básicos de salud, educación y vivienda (Kreimer y Figueroa, 2008). En la práctica, como analizaremos en las siguientes secciones, la campaña hizo énfasis en la discriminación e indiferencia que sufre este sector de la población indígena, en tanto dificultan aún más que niños y niñas puedan acceder a sus derechos sociales.

El posicionamiento del organismo internacional encuentra sus raíces en los principios y disposiciones de la Convención Internacional de los Derechos del Niño (CIDN) y su ratificación posterior en el año 2002 durante la Sesión Especial de la Asamblea General de las Naciones Unidas en Favor de la Infancia, en la que se enfatizó la necesidad de visibilizar las especificidades de niños y adolescentes indígenas y se instó a los estados a asegurar el acceso a una educación de calidad que respete el "patrimonio cultural" y consolide la identidad de los niños indígenas (Centro de Investigación Innocenti, $2004)^{4}$.

Es entonces clara la creciente preocupación por los niños y adolescentes indígenas en el marco de algunos organismos internacionales. En Argentina, esta atención se ha concretado en diversas actividades realizadas por UNICEF, tales como espacios de recreación y encuentro con niños de comunidades indígenas, la celebración del "Día del niño de montaña" o la publicación de material gráfico y bibliográfico, referido principalmente a la educación, a la salud materno-infantil y al acceso a la justicia, temáticas sobre las que, además, se llevaron adelante encuentros de intercambio de experiencias. Como parte de dichas iniciativas, también se elaboró la "campaña por los derechos de la niñez y adolescencia indígena" ${ }^{5}$ que fue difundida durante 2009 a través de un video, dos spots para radio y dos producciones gráficas.

Los materiales de la campaña fueron publicados, por un lado, en internet y las redes sociales, donde tuvieron mayor circulación, particularmente en páginas web sobre noticias internacionales de voluntariado y ecología (UNICEF, 2009). Por otro lado, también se difundieron, aunque en menor medida, en los medios audiovisuales y gráficos considerados de alcance nacional, con sede en Buenos Aires. A continuación

${ }^{4}$ El Instituto Innocenti es un centro de investigaciones creado por UNICEF en 1988.

${ }^{5}$ La campaña recibió aval de la cámara de Diputados de la Nación Argentina, que la declaró de interés el 17/09/2009. 
describiremos brevemente cada pieza de la campaña, para desarrollar su análisis en el siguiente acápite.

El video, filmado en Rodero, pequeña localidad de la provincia de Jujuy, transcurre en un paisaje puneño típico del Noroeste Argentino, con niños y niñas que entran y salen de escena haciendo una representación que remite a diferentes problemas medioambientales a nivel planetario, como la deforestación y el calentamiento global. Disfrazados de árboles o de ballena, cargan carteles con frases explicativas de cada situación, con una música de fondo y sin hablar, hasta que al final un niño dice "estamos apoyando estas causas porque sabemos muy bien lo que es que te ignoren". Luego una voz masculina adulta en off agrega la frase slogan de la campaña: "Los niños, niñas y adolescentes indígenas tienen derechos que son ignorados y eso contribuye a su exclusión. Hagamos que sus derechos se cumplan".

Los spots radiales tienen una lógica similar. En el primero escuchamos las voces de niños y niñas que sucesivamente piden en inglés que su pueblo sea nombrado, con la frase "say 'the tobas'/'the wichís'/ 'the coyas'/ 'the huarpes', etc". Al finalizar, una voz adulta y masculina cierra con el slogan de la campaña. En el segundo, se oye a un niño que habla de las necesidades de "los niños de las comunidades indígenas...", pero que es constantemente interrumpido por ruidos característicos de la ciudad (un teléfono, una bocina, etc.) que impiden que se escuche en qué consisten tales necesidades. Solamente se oyen algunas palabras o expresiones entrecortadas: "necesitamos (ruido) para ir a la escuela. Y también nos hace falta (ruido) para estudiar. Además muchos no tenemos (ruido) para conectarnos. Y sobre todo no tenemos (ruido) para jugar como todos los chicos", tras lo cual se oye claramente y sin interrupciones la misma voz masculina de los otros materiales, que repite el slogan.

La campaña gráfica consta de dos afiches muy similares entre sí, que consisten en fotografías tomadas en lo que claramente parece un museo de tipo decimonónico. En ambas se enfocan vitrinas de exhibición en las cuales se ubican, en un caso, una niña sola, y en el otro, una niña y un niño tomados de la mano, en poses estáticas, como si estuviesen embalsamados. Los niños aparecen fotografiados casi sin luz y ambientados en un paisaje de desierto. Hacia el borde inferior se lee en un recuadro: "No esperemos a que dejen de existir para saber que existen" y luego, el ya citado slogan.

Realizada esta breve caracterización de los recursos comunicativos empleados en la campaña, plantearemos algunas reflexiones que, desde una mirada antropológica, nos permitan profundizar el análisis del modo en que la niñez indígena es representada. Procuramos problematizar las retóricas universalizantes, encontrando lo "local de su producción y difusión, así como los efectos concretos de su implementación y usos particulares" como propusiera Schuch (2009). Enfocaremos entonces la mencionada campaña atendiendo a los distintos modos en que los enunciados sobre la universalidad atribuida a dichos derechos se entrecruzan con la diversidad cultural.

\section{Exotismo, proyección al pasado y participación indígena}

Los materiales descritos, junto con información relevada etnográficamente, ofrecen muy interesantes vetas para un análisis antropológico, que abordaremos a continuación en 
dos facetas. Por una parte, aquella vinculada al carácter abstracto e indeterminado de la campaña y las tensiones entre particularidad cultural y supuesto carácter universal de la niñez. Por otra parte, una necesaria lectura antropológica de la exotización, ruralización y proyección al pasado de la niñez indígena, así como también de la participación indígena en este tipo de iniciativas.

\subsection{Del dicho al hecho...}

En primer lugar, resulta significativo que frente a la inconmensurable vulneración de los derechos de los niños y niñas indígenas en la Argentina, la principal acción del organismo internacional abocado a la infancia haya sido una campaña de difusión que, por definición, no apunta a mejorar directamente las condiciones de vida de estos niños y que, dada su vaguedad -que abordaremos en los siguientes párrafos- no consiguió instalar la temática en la agenda pública.

En parte esto puede comprenderse por el hecho de que las campañas de difusión constituyen una estrategia recurrentemente utilizada por UNICEF, orientada a la visibilización y concientización acerca de diferentes problemas que afectan a la niñez. Tal como lo expresara una de sus funcionarias: "nosotros detectamos una problemática y buscamos el modo de hacerla visible, de brindar herramientas para que la población la visibilice (...), visibilizar que hay trabajo que hacer", dejando el desarrollo de políticas públicas, su implementación y la gestión total de las mismas a los estados implicados en cada caso.

$\mathrm{Al}$ respecto, es importante situar esta cuestión en la dinámica con que se manejan las grandes organizaciones y agencias internacionales con base en países centrales, según los distintos contextos de su acción. Como ha relevado Tissera (2014) en su etnografía del campo de la defensa de los derechos del niños a nivel global, "Unicef cumple tres tipos de roles diferentes: en los países desarrollados 6 , su función es principalmente la de captar fondos; en los países intermedios (como Colombia o Argentina), fortalecer las capacidades del estado, o sea, apoyarlo para que desarrolle cierto tipo de políticas públicas; en los países más pobres, presta servicios directos" (71).

Sin desmerecer tales esfuerzos -que forman parte de lo que ha dado en llamarse "advocacy" o "abogacía"- desde una perspectiva antropológica resulta relevante apuntar que los discursos mediáticos sobre determinadas poblaciones "privilegiadas" en materia de derechos humanos suelen implicar un significativo riesgo de reificación, como lo han advertido Fonseca y Cardarello (1999). Así, categorías como "niños" e "indígenas" quedan cristalizadas y folklorizadas en imágenes masivas que circulan y se repiten sin habilitar el análisis profundo de la desigualdad que sufren estos grupos y, mucho menos, de las causas estructurales de la misma. Encontramos en esto una significativa confluencia con el modo en que las problemáticas indígenas han sido tratadas por el estado argentino, cuyo tardío reconocimiento de los derechos indígenas ha sido calificado por distintos investigadores como "tibio" (Mombello, 2002),

${ }^{6}$ No es nuestro cometido aquí abordar la discusión sobre este tipo de clasificación de los países. 
meramente enunciativo o como un pseudo-reconocimiento, en el sentido de arrogarse la mayor parte de las veces "la prerrogativa de interpretar las 'verdaderas necesidades' de la gente, como necesidades a ser organizadas, tuteladas y resueltas la mayor parte de las veces por agentes externos", cuyo compromiso con la implementación de las políticas públicas necesarias para la concreción de tal reconocimiento ha sido bajo (Briones y Carrasco, 2005: 229).

Volviendo a la iniciativa de UNICEF que aquí nos ocupa, planteamos que sus efectos sobre el debate público en torno a los derechos de niños y adolescentes indígenas resultan problemáticos, pues en la campaña no se mencionaron derechos puntuales que estuvieran siendo vulnerados, ni los procesos sociales que generaron dichas vulneraciones, sino que se insistió en que los niños indígenas "tienen derechos que son ignorados". Así, a diferencia de otras campañas en las que UNICEF también recortó un colectivo y elaboró un decálogo o listado de derechos específicos para promoverlos (UNICEF, 2014), en este caso quedó totalmente indeterminado de qué derechos se trataba.

Consideramos que de este modo se desperdició su potencial interpelador, que podría haber contribuido a instalar las injusticias que afectan a la niñez indígena como un problema "público", una "cuestión socialmente problematizada" (Oszlak, 1978). Es decir, un asunto que se problematiza en tanto que ciertas clases, fracciones de clase, organizaciones, grupos o incluso individuos estratégicamente situados creen que puede o debe hacerse "algo" al respecto, promoviendo su incorporación en la agenda de problemas socialmente vigentes.

\section{2. ¿Niñez hay una sola?}

Fonseca y Schuch (2009) ofrecen elementos para pensar la distancia entre los discursos generales sobre los derechos de los niños y las situaciones sociales concretas de vulneración de esos derechos, al plantear que tales discursos suelen universalizar la condición hegemónica de la infancia, la idea de una "infancia universal" (vinculada a la inocencia, la protección y la preparación para la vida adulta), pero que esto no equivale a universalizar las condiciones de acceso a derechos que habiliten experiencias infantiles menos desiguales.

Al hacer eje en los derechos de los niños indígenas, la campaña de UNICEF pone en juego una tensión implícita entre el carácter universal atribuido a los derechos de la niñez en general y los derechos particulares reconocidos a los pueblos originarios, anclados en especificidades culturales y fundados en su preexistencia al estado. De esto se desdobla, a su vez, una tensión entre la definición liberal, que centra los derechos universales en los individuos -el niño, cada niño, como "sujeto de derechos"-, y la concepción de los derechos como atributo de colectivos o comunidades, como son los derechos de los pueblos originarios. En efecto, la focalización en los niños evidenciada

7 En el caso de la problemática de salud pública de la prematurez, UNICEF Argentina elaboró en 2010 el decálogo de los derechos de los niños nacidos de parto prematuro y desde entonces organiza la Semana del Prematuro, una campaña a nivel nacional que incluye diversas acciones para la promoción y el cumplimiento de dichos derechos. 
por la campaña, por un lado concuerda con su definición como sujetos especiales de derecho, en razón de su edad particular pero, a la vez, al atribuir implícitamente a ese momento vital una base natural y generalizada en la especie humana, se ancla en una noción universalizante de la infancia.

Numerosos autores han analizado el proceso de construcción de esa imagen totalizadora de la niñez (Ariès, 1987; Jenks, 1996), en el marco del surgimiento de la modernidad como nuevo paradigma cultural (De Sousa Santos, 2010), vinculado al proceso de cambio de formación social que marca el fin del feudalismo y el origen de la era del capital (Marx, 2012 [1867]), el ascenso de la burguesía y el desarrollo del colonialismo. Así, desde una visión hegemónica en las sociedades occidentales, la niñez se construyó no desde la diferencia (alteridad) sino desde la desigualdad; por eso niños y niñas han sido históricamente considerados irracionales e incapaces, sustrayéndolos "de la historia y del conflictivo contexto socioeconómico y político, negando su agencia social" (Szulc 2006: 32).

Sin embargo, tal como lo han mostrado numerosos estudios etnográficos en América Latina (Cohn, 2002; Colangelo, 2003; Enriz y García Palacios, 2008; Hecht y García Palacios, 2010; Szulc, 2007; Tassirani, 2007), esta concepción sobre la niñez no corresponde más que a una versión entre las muchas que han construido las distintas sociedades ${ }^{8}$, pues el ciclo vital ha sido organizado e interpretado de modos histórica y culturalmente variables. Aún más, el percibir la vida como un proceso de maduración gradual implica en sí mismo una concepción cultural singular, vinculada con nociones específicas acerca del tiempo, de las transformaciones y de la persona (Thorne, 2004).

Si bien es cierto que muchas de las ideas acerca de la supuesta incapacidad e incompetencia de niñez han sido debatidas por la comunidad internacional y se ha pretendido desplazarlas por una "perspectiva de derechos", basada en el reconocimiento de los niños como "sujetos" participativos y detentores de dichos derechos, en la práctica tal perspectiva, al ser formulada en términos abstractos, suele reactualizar la operatoria universalizante y cosificante de la niñez.

Es sobre todo a partir de la Convención Internacional de los Derechos del Niño que se consagra la retórica universalizante de la infancia, definida a partir de procesos de desarrollo- biológicos, psicológicos y vinculares- comunes a todos los niños y niñas. Cabe destacar que dicha Convención se elaboró en un contexto específico, poniendo en juego relaciones de poder e intereses geopolíticos diversos, y por tanto no únicamente legitimando y naturalizando determinada perspectiva, sino a la vez excluyendo otras (Barna, 2012). El enfoque universalista, pasa a articularse entonces con la noción del niño como sujeto y, más específicamente, como "sujeto de derechos" (Vianna, 2002), a partir de una serie de procesos que "[...] implican no solamente un idioma de derechos

${ }^{8}$ Desde esa perspectiva occidental del tiempo y de la vida como una progresión lineal, la niñez se ha caracterizado como un periodo de transición, una realización futura antes que una experiencia del presente. La necesidad de garantizar y guiar este tránsito ha dado lugar a los procesos sociales de crianza y de educación y, a la formulación de políticas públicas destinadas a la protección y tutela de los niños en tanto "capital humano de la nación" y sus familias (Colangelo, 2004). 
formales, sino también un conjunto de valores sobre la familia, la autoridad, el género, la seguridad y la armonía social que terminan constituyendo a la infancia como un sujeto moral" (Schuch, 2009: 251).

Esta concepción de una infancia unívoca, sujeto de derechos universales, deviene problemática desde una mirada antropológica atenta a las particularidades y relaciones socioculturales y a sus procesos de producción. Al respecto, Wilson (1997) advierte sobre la escasa contribución de pensar en términos polares universalismo/ relativismo, proponiendo en cambio abordar los derechos humanos en tanto "contexto". Se requiere entonces un análisis situado que enfoque los significados y usos particulares, y repare en los "derechos del niño" como "procesos discursivos" (Fonseca y Cardarello, 1999) producidos en determinados contextos sociohistóricos. Esta mirada problematizadora permite visualizar cómo ese "frente discursivo" de los derechos del niño genera un acceso desigual a la condición hegemónica de infancia para aquellos niños que viven su niñez desde la intersección de factores de subordinación social como la clase, el género o la identidad étnica. La discusión, por lo tanto, lejos de centrarse en evaluar las distancias entre un abstracto ideal (los derechos reificados como figura axiomática) y las prácticas concretas de los actores involucrados, debería habilitar un análisis situado de los procesos particulares y los atravesamientos de poder presentes en cada instancia en que se apela a tales derechos.

Volviendo a poner el foco en las campañas globales por los derechos del niño impulsadas por UNICEF, Vinelli (2006), en su análisis de la campaña "Los dibujos animados en pro de los derechos del niño", muestra cómo la figura del niño no aparece situada en lugares concretos, ni se representan las particularidades contextuales y locales de cada cultura. A partir de estas apreciaciones, la autora se pregunta si una campaña con estas características no impediría ver "que los derechos del niño, en vez de ser solamente una serie de principios 'abstractos', se manifiestan en situaciones concretas y cotidianas" (Vinelli, 2006: 201).

En el caso que aquí analizamos, por el contrario, la iniciativa parecía apuntar a grupos particulares de niños y adolescentes - "la niñez y la adolescencia indígena". Sin embargo, las especificidades de los niños que la campaña pretendía mostrar quedaron reducidas a su pobreza, siendo por ejemplo caracterizados por un alto funcionario de UNICEF Argentina, al presentarse esta campaña, como "el sector más vulnerado por la falta de acceso a condiciones dignas de educación de calidad, servicios de salud apropiados, nutrición, agua y saneamiento, entre otros". En ese sentido, desde una perspectiva antropológica, podemos advertir cómo la interpretación y promoción de los derechos del niño/a en ámbitos específicos generalmente se ve condicionada por los sentidos y prácticas hegemónicas vigentes en cada campo. Así, la campaña fue moldeada claramente por la tendencia de los organismos internacionales a circunscribir la cuestión indígena y las problemáticas infantiles a la condición de pobreza, hoy día enunciada como "vulnerabilidad" (Szulc, 2007), desde una perspectiva etnocéntrica o,

9 Campaña lanzada en 1999 con motivo del décimo aniversario de la Convención Internacional de los Derechos del Niño. 
en palabras de De Sousa Santos (2010), desde un "localismo globalizado"10. En este caso, ello puede advertirse en el intento de universalizar determinada definición de infancia, olvidando no solamente las particularidades culturales, sino las condiciones materiales de los distintos grupos sociales y los procesos subyacentes que han producido tal desigualdad entre distintas sociedades, así como entre distintos sectores dentro de cada una de ellas, (Katz, 1996).

\subsection{Al rescate de la niñez indígena}

Los documentos elaborados por UNICEF para sustentar la realización de la campaña se fundan en la "vulnerabilidad de la población indígena infantil argentina" (Kreimer y Figueroa, 2008:7). Si bien coincidimos en que el colectivo infantil indígena está atravesando una particular situación que merece ser visibilizada (Castillo, 2011), creemos imprescindible indagar qué criterios sustentan la promoción de estos derechos específicos, y cómo son representados los niños indígenas y sus derechos en los materiales de la campaña.

En ese sentido resulta relevante señalar los riesgos de haber utilizado la ya citada vulnerabilidad como criterio, que emerge como un atributo de los sujetos y las poblaciones, no permitiendo advertir los procesos sociales, económicos y políticos involucrados en la conformación de las condiciones sobre las que, al usarla, quiere alertarse (Frankenberg Robinson y Delahook, 2000). En el caso analizado, esto se evidencia, por ejemplo, en el llamamiento de un alto funcionario de UNICEF quien, en el acto de presentación de la campaña, exhortó insistentemente a "no perder el foco", planteando que la discusión sobre los derechos colectivos de los pueblos indígenas podría "opacar" la cuestión de los derechos del niño.

De este modo, la focalización en la infancia indígena se corresponde con la tendencia característica de la gubernamentalidad neoliberal de recortar sujetos específicos de intervención obviando cómo su situación se configura en la intersección de múltiples dimensiones sociales -etnia, edad, género, clase- y es atravesada por problemas estructurales. Es preciso entonces señalar que el carácter focalizado y a la vez poco preciso de la campaña ha implicado una negación de la incidencia que la vulneración de los derechos colectivos de los pueblos indígenas tiene sobre las vidas de los niños, en consonancia con una marcada tendencia de la política indigenista local de reconocer a los pueblos indígenas como "sujetos de asistencia", en lugar de como "sujetos de derecho" (Lenton y Lorenzetti, 2005: 319). Concretamente, es preciso considerar cómo el avance de la frontera cultivable y la irresuelta situación territorial afecta a todo el colectivo indígena (Buliubasich, 2013) o, en las provincias petroleras, cómo la producción de hidrocarburos acarrea daño ambiental y cultural (Lenton, 2009: 6) a comunidades enteras, no únicamente a sus niños y niñas.

Resurge entonces el interrogante sobre qué definición de niñez opera en esta iniciativa, si se entiende que atender a derechos colectivos de los pueblos indígenas

${ }^{10} \mathrm{El}$ autor refiere de este modo al proceso por el cual "una entidad local tiene éxito en extender su alcance sobre el globo" (De Sousa Santos, 2010: 62) y, al lograrlo, rivaliza con entidades locales. 
"opacaría" el cumplimiento de los derechos de la infancia. En este sentido, advertimos que en las producciones gráficas y audiovisuales de la campaña se aísla a los niños del entramado social en que viven, al presentarlos como niños solos, evocando así el fantasma del abordaje tutelar de la minoridad, hoy legalmente derogado en la Argentina, pero aún vigente en la práctica y en el imaginario social hegemónico. Al respecto, en reuniones posteriores a la presentación oficial de la campaña diversos referentes indígenas manifestaron su preocupación por la descontextualización de los niños que aparecen en los distintos materiales: "porque ahí lo que se ve es un niño solo, separado de todo, sin su comunidad, sin su familia, sin identidad, sin historia (...) como si los estuvieran ofreciendo en adopción".

Expresiones como la citada evidencian cómo tales imágenes tocan un punto sensible para la población indígena, haciendo reverberar experiencias remotas y recientes de despojo. Por un lado está ampliamente documentada la práctica sistemática de sustracción y distribución de niños indígenas para servidumbre tras la conquista militar de los territorios indígenas aún autónomos, a fines de siglo XIX (Lenton, 2009; Szulc, 2007). Por otro lado, tal práctica - central en la definición de lo ocurrido como un genocidio- permanece en la memoria colectiva y es percibida como continua, vinculada en el presente con numerosas adopciones de niños indígenas denunciadas como irregulares (Confederación Mapuche Neuquina, 1994; Datachaco, 28/04/2014).

Otro de los ejes de nuestro análisis refiere al modo en que se presenta lo indígena en los materiales de la campaña. En primer lugar, como anticipamos, lo que abiertamente se enuncia en distintos formatos es su condición de vulnerabilidad que, desde una matriz de pensamiento neoliberal, termina siendo reificada al negarse los procesos que la producen. Algunos autores vienen señalando esto como una característica recurrente del accionar de los organismos y ONG internacionales, como por ejemplo lo ha planteado Picas Contreras (2006: 6):

En los medios de comunicación, el llamado Tercer Mundo se representa con un solo rostro: el del desastre (...). La primera -y, a veces, única- imagen que se difunde es la de la pobreza (de bienes materiales) que lo asola. Los seres humanos que lo habitan devienen emblema de sufrimiento. Como corolario, se deduce que es preciso socorrerlos.

En este sentido, si bien es claro que UNICEF Argentina desarrolla iniciativas diversas, tematizando variadas cuestiones, en el caso de la campaña sobre los derechos de la niñez y adolescencia indígenas resultó omnipresente la representación de esta población meramente como niños pobres, y la definición de sus problemáticas en términos exclusivamente de pobreza. Es por ello que, si bien no es nuestro cometido sobredimensionar nuestra mirada crítica reclamando a UNICEF que resuelva cuestiones de fondo -que como anticipamos una campaña audiovisual por definición no puede resolver- sí nos parece pertinente y relevante analizar antropológicamente el modo en que a través de esta campaña se decidió retratar a los niños indígenas y sus derechos, no visibilizando problemáticas cruciales; punto al que volveremos más adelante.

En segundo lugar, el spot televisivo y las producciones gráficas difundieron la problemática, emplazando la vida de los niños en ámbitos rurales, lejos de los centros urbanos. De este modo, se reactualiza el estereotipo que sobre los indígenas ha sido 
hegemónico en nuestro país, por el cual "desde una perspectiva esencialista de las pertenencias e identidades, se ha instituido la vida rural como condición necesaria del «auténtico» indígena" (Szulc 2004:171). Esta ruralización de lo indígena supone una mirada descontextualizada no solamente de la población indígena y de su problemática, sino también una esencialización romántica del ámbito rural como prístino, anclada en una oposición respecto del ámbito urbano -al "suprimir el trabajo campestre y las relaciones de poder a través de las cuales se organiza ese trabajo (...)" (Williams, 2001: 75).

A su vez, en el video producido por la campaña, resalta el tratamiento del entorno de la puna como telón de fondo para visibilizar problemas ambientales muy distantes de la realidad comunitaria de Rodero, desde una perspectiva fisicalista de la naturaleza. Se presenta así la naturaleza como dada, en lugar de como "producto histórico" resultado de una multiplicidad de procesos económicos, políticos y sociales que han "destruido o amenazado las condiciones naturales de la reproducción de la misma" (Beck, 2006: 113).

En este sentido retomamos lo planteado por Szulc en cuanto a cómo los pobladores rurales "al igual que en su momento los primitivos han sido concebidos como seres pasivos, meros espectadores de una realidad inmutable que se les impone, portadores de tradiciones que no pueden modificar" (2004:168). Es notable cómo el rol de los niños indígenas en el spot se reduce a entrar y salir de escena personificando elementos de la naturaleza o sosteniendo carteles que aluden a la protección de las ballenas o la preservación de los bosques en abstracto, consignas ambientalistas ajenas a su trayectoria de vida, o a pronunciar un slogan en que empatizan con la naturaleza, "estamos apoyando estas causas porque sabemos muy bien lo que es que te ignoren".

Así, en tercer lugar, la "ambientalización" de la problemática indígena que presenta la campaña, no obedece únicamente a la legitimidad que el discurso ecologista confiere a los conflictos sociales en el neoliberalismo (Lopes, 2006) sino que a su vez contribuye a la proyección de la población indígena a tiempos pretéritos. Pues al homologar las problemáticas de la niñez indígena con la crisis de los bosques o la cuasi extinción de la ballena azul, se reproduce el postulado de sentido común que históricamente ha considerado a la población indígena como en vías de extinción, como en su momento se advirtió en una nota periodística (Página 12, 2009). Esto se vincula con el proceso de "exclusión de los pueblos indígenas de la «identidad nacional», que implicó relegar su existencia a un tiempo pasado remoto, previo a la conformación del estado-nación. Fueron concebidos como "rémoras" que dificultaban el progreso, vestigios de una sociedad que se pretendía transformar" (Szulc, 2004:171). Dentro de este modelo, los indígenas han tenido un bajo nivel de visibilidad, siendo más bien "una presencia fantasmagórica y prescindible, siempre destinada a desaparecer y siempre anacrónica por no hacerlo del todo" (Briones, 2004: 77).

En ese sentido, al presentar en la campaña gráfica a los niños indígenas como parte de una exhibición en un museo decimonónico -bajo el slogan "no esperemos a que dejen de existir para saber que existen"- se refuerza aún más la proyección de esta población al pasado, negando la legitimidad de su existencia en el presente. Resulta llamativa esta decisión, habiéndose desarrollado recientemente en la Argentina numerosos conflictos 
por la presencia de restos humanos indígenas en las colecciones de museos, objeto de numerosos reclamos de restitución por parte de representantes contemporáneos de esos pueblos. ${ }^{11}$

La construcción de sujetos sociales como piezas de museo resulta en sí compleja y se enmarca en procesos de subordinación y sometimiento más amplios que sufrieron los pueblos indígenas en el proceso de construcción de la nación (Tamagno, 2009; Lazzari, 2011). Implica detener y fijar al sujeto en el tiempo, desgajado de las relaciones sociales en las que participaba y de todo vínculo posible con el presente, tomándolo al mismo tiempo como representación de una totalidad: el "ejemplar" de una "raza" o de un grupo, y como vestigio cristalizado del pasado: una "reliquia". Tal como lo señala Rodríguez, "mediante un doble juego de inclusiones y exclusiones, los restos óseos de personas indígenas fueron exhibidos como el pasado de la patria, excluidos del futuro [...]" (Rodríguez, 2011: 3).

En vista de estas consideraciones, situar a los niños indígenas en una vitrina de museo y con un mensaje que remite a pueblos que pueden extinguirse, reactualiza -aunque este no haya sido el objetivo- el lugar subordinado de los pueblos indígenas en la construcción hegemónica de la historia y del patrimonio cultural de la Argentina. En otras palabras, si bien con esas imágenes se propone visibilizar las vulneraciones de los derechos de los niños indígenas contemporáneos, se logra el efecto contrario, exotizando implícita pero evidentemente a los niños indígenas (Szulc, 2007), al volver a situarlos como parte del "patrimonio muerto" en los términos en que lo planteara Ratier (1997).

\subsection{La participación en cuestión}

Uno de los derechos reconocidos a los pueblos indígenas -por ejemplo por el convenio 169 de la OIT, que goza en la Argentina de rango constitucional- es su derecho a participar en las decisiones sobre temas que les conciernen. En el caso que aquí nos ocupa, pudimos relevar cómo en el acto de lanzamiento de la campaña, diversos oradores de UNICEF enfatizaron que se trataba del producto de un trabajo conjunto con referentes indígenas, proceso que procuraron "sea intercultural". No obstante, existe evidencia de que la participación en la elaboración se limitó a una persona, la docente del paraje donde se filmó el spot televisivo, siendo otros representantes indígenas convocados a una reunión el mismo día de la presentación pública de la campaña, "con ya todo cocinado", como planteara uno de ellos. Así, se reactualizó una tendencia de la política indigenista estatal argentina de reducir la "participación indígena" a la designación de una persona indígena como representante o funcionario (Falaschi, Sánchez y Szulc, 2005: 195). Al respecto, referentes de organizaciones indígenas manifestaron que

11 Un caso emblemático fue el de Damiana, niña indígena Aché apropiada en 1896 en Paraguay con menos de un año de vida -luego de una expedición en la que masacraran a parte de su familia- y cosificada por la "ciencia", sometiéndola a estudios biométricos y craneométricos y fotografiándola desnuda. Luego de su muerte, su cuerpo pasó a formar parte de las colecciones del Museo de Ciencias Naturales de La Plata, Argentina. Recientemente, tras el arduo reclamo de su comunidad y el eco de esto en sectores comprometidos sus restos fueron restituidos. 
resulta problemático el hecho de que con la participación de una persona indígena se dé por cubierta la representatividad, y lamentaron el haber tenido que "pelear" para que los dejaran hablar en el acto.

Ello constituye un ejemplo de que, tal como lo analiza Lenton, los avances conseguidos en las reformas constitucionales y en los convenios internacionales en términos de reconocimiento de derechos indígenas no se traducen en la práctica, pudiendo constatarse en el accionar de gran parte de los organismos abocados a la política indigenista la "persistencia de paradigmas de subordinación por sobre la participación y de un enfoque integracionista por sobre la declamada interculturalidad" (Lenton, 2009: 80). Esta tendencia se advierte claramente en la campaña que analizamos, no solamente por haber minimizado la participación indígena sino, a su vez, porque al centrarse en los universalizados derechos del niño -sin mencionar qué derechos de los niños indígenas están siendo vulnerados y dejando fuera los derechos colectivos específicos- la problemática queda reducida a una cuestión de visibilidad y de necesidades básicas insatisfechas, como se evidencia particularmente en el segundo de los spots radiales -descrito ya más arriba. ${ }^{12}$

Así, los materiales y el proceso de elaboración de la campaña reactualizan dinámicas asociadas al neoindigenismo, que engloba "prácticas que renuncian, en lo explícito, a un proyecto de asimilación vinculado al indigenismo clásico pero concretan, en los hechos, estilos restringidos de consulta y participación indígena. Prácticas asimismo que, imbuidas de un proyecto de nivelación de sujetos económicamente sumergidos o 'ciudadanos incompletos', buscan promover su desarrollo en base a actitudes paternalistas" (Briones y Carrasco, 2005: 229). En síntesis, podemos afirmar que en el caso de la campaña por los derechos de los niños, niñas y adolescentes indígenas, UNICEF no cumplió adecuadamente con la consulta previa a los pueblos indígenas y trivializó la participación (Lenton, 2009).

Asimismo, es de destacar que el día de la presentación pública de la campaña, en un céntrico teatro de la Ciudad de Buenos Aires, varias hileras de asientos estaban ocupadas por niños y niñas, que no fueron presentados ni participaron más que como asistentes del acto. Asimismo, si bien diferentes niños protagonizaron las distintas producciones, no nos consta que hayan participado en el diseño o elaboración de las mismas. Pues "para el modelo occidental hegemónico la niñez se vincula con la política solamente como objeto de protección y asistencia" (Szulc, 2013), quedando el escenario de la política y de los asuntos públicos en general como ámbito exclusivo del hombre adulto racional (Rabello de Castro, 2012). Esto ubica a niños y niñas en una posición paradójica, ya que si bien emergen como los sujetos de derecho más legítimos y prioritarios, sus voces permanecen ausentes en el marco de implementación de políticas públicas (Batallán y Campanini, 2008; Llobet, 2006). Así pues, tratándose no solamente de indígenas, sino de niños indígenas, la trivialización de su derecho a la participación se acentuó aún más. La enunciada participación resulta así problemática,

12 Ver transcripción de dicho spot radial en las páginas 6-7 del presente artículo, donde se advertirá que, si bien elípticamente, se alude principalmente a necesidades básicas insatisfechas. 
y debe comprenderse en su contexto, pues obedece también a una tendencia de lo que De Sousa Santos (2005) ha denominado matriz de gobernación neoliberal, en la cual la participación se basa en un principio de selección según el cual únicamente algunos actores, intereses o voces son admitidos a participar (14).

\section{A modo de cierre}

En este trabajo hemos analizado las construcciones sobre la niñez, sobre lo indígena y sobre sus derechos producidas a través de la "campaña por los derechos de los niños y adolescentes indígenas" de UNICEF Argentina, desde una perspectiva antropológica. La misma nos ha permitido problematizar, en diálogo con nuestras investigaciones más amplias, la supuesta universalidad de los "derechos de los niños", para plantear que estos solamente cobran entidad en la diversidad y desigualdad que constituyen a la niñez y la adolescencia indígena en nuestro país.

En ese sentido, como anticipamos, el objetivo no ha sido realizar una crítica a la campaña en sí misma, sino abordarla como una producción de acciones y de materiales "buenos para pensar".

Hemos comenzado reflexionando acerca de la distancia entre los discursos generales y abstractos acerca de los derechos de niños y adolescentes indígenas y las concretas vulneraciones de derechos que los afectan - ligadas en gran parte al histórico despojo de sus territorios-, para señalar que esta omisión de causas estructurales y procesos sociales ha debilitado el potencial interpelador de la campaña realizada por UNICEF.

En consonancia con lo anterior, señalamos las tensiones que surgen entre derechos universales y específicos, individuales y colectivos, presentes en los discursos acerca de los derechos de la niñez indígena - tensiones que exceden ampliamente el marco de la campaña considerada.

A partir de ello, buscamos evidenciar cómo, aun cuando los derechos del niño vienen ganando notable visibilidad en las políticas públicas y de los organismos internacionales, su puesta en práctica supone una definición también acerca de otros derechos en juego, como los derechos indígenas, sociales, laborales, ambientales, que aunque en ocasiones pueden verse potenciados, parecen en este caso haber quedado relegados ante la focalización en la niñez y en sus problemáticas en términos más bien individuales..

En ese sentido, sostenemos que la escisión de los niños indígenas respecto de su entramado social realizada por la campaña aquí analizada, tiene consecuencias políticas -deseadas o no- y amerita así esta revisión crítica, a fin de evitar que futuras producciones refuercen en el sentido común de nuestro país imágenes que terminan contribuyendo a la vulneración de los derechos de los niños indígenas.

Encontramos asimismo en el caso analizado una convergencia entre ciertos abordajes sobre los niños y sobre los pueblos indígenas, que coinciden en el modo de construir problemas sociales y sujetos colectivos. Pues consideran -quizá implícitamente- a unos y otros como grupos en sí mismos, a partir de ciertas "esencias" antes que como producidos históricamente en el entrecruzamiento de relaciones de diversidad cultural y desigualdad social; y de este modo, en el caso de los niños indígenas, aparece redoblada 
la esencialización. Al respecto, hemos visto de qué manera los materiales gráficos de la campaña privilegian sentidos que reifican la vulnerabilidad de los niños indígenas y proyectan su presencia a ámbitos rurales y tiempos pretéritos.

Consideramos relevante señalarlo, pues las conceptualizaciones abstractas y esencialistas sobre niños y sobre indígenas obstaculizan el abordaje de problemáticas concretas, lo cual tiene enormes implicaciones en el modo en que se proponen y realizan intervenciones con estos colectivos.

Ello se ve reforzado por la escasa posibilidad de participación que han tenido las comunidades y organizaciones indígenas y sus niños y adolescentes en la elaboración de los materiales de la campaña, como ya hemos planteado.

En síntesis, los materiales analizados se han revelado ricos y sugerentes para problematizar no solamente la niñez y la cuestión indígena, sino también la noción de derechos, que aparece hoy como "lingua franca" incuestionada, preferida por los medios de comunicación masiva y los entes financiadores (Merry, 2006). Al respecto, hemos planteado en este trabajo que existen concepciones diferentes sobre los derechos, que en tanto pueden utilizarse en diversos momentos y contextos con diversas interpretaciones, forman parte de un campo de disputa que hemos procurado entonces analizar más allá de lo legal. Nos propusimos así distanciarnos de una mirada sacralizadora, para abordar los derechos humanos, y los derechos del niño indígena más específicamente, desde los sentidos y usos que se producen en un caso concreto, situado histórica y contextualmente.

Así, el trabajo realizado nos permitió advertir cómo esta campaña está enraizada en nociones y prácticas características de la gubernamentalidad neoliberal, en la cual la juridización de la vida social ha conllevado un proceso de despolitización (De Sousa Santos, 2005). Es así que numerosas organizaciones procuran legitimar su accionar presentándose como a-políticas, como consideramos que ocurre en el caso aquí analizado, en el cual UNICEF ha procurado promover los derechos de los niños indígenas, sin darles contenido ni aludir a los conflictivos procesos por los cuales son vulnerados, como ya se ha explicado.

Desde una perspectiva antropológica, entonces, la campaña analizada nos parece interesante para reflexionar sobre cómo construir una noción de derechos que no sea abstracta y genérica, sino construida constantemente a partir de las prácticas e interacciones cotidianas, comprendiendo relacionalmente a los distintos grupos sociales, en lugar de focalizada y descontextualizadamente.

\section{Bibliografía}

Ariès, P. (1987): El niño y la vida familiar en el Antiguo Régimen, Madrid, Taurus.

Barna, A. (2012): "Convención Internacional de los Derechos del Niño. Hacia un abordaje desacralizador", KAIROS. Revista de Temas Sociales, 16 (29), pp.1-19.

Beck, U. (2006): La sociedad del Riesgo, Barcelona, Paidós.

Batallán, G. y S. Campanini (2008): "La participación política de niñ@s y jóvenesadolescentes", Cuadernos de antropología social, 28, pp. 85-106. 
Briones, C. (2004): "Construcciones de Aboriginalidad en Argentina", Bulletin de la Société Suisse des Americanistes, 68, pp.73-90.

Briones, C. y M. Carrasco (2005): "La lucha por la tierra. (Neo)indigenismo estatal y producciones indígenas en Argentina (1985-1999)", en E. Cruz y R. Paoloni (eds.), La propiedad de la tierra: Pasado y presente. Arqueología, historia y antropología sobre la problemática de la propiedad de la tierra en la Argentina, Jujuy, Universidad Nacional de Jujuy, pp. 228-265.

Buliubasich, C. E. (2013): "La política Indígena en Salta. Límites, contexto etnopolítico y luchas recientes", Revista RUNA, 34(1), pp.59-71.

Castillo, M. (2011): Brechas ODM en los Pueblos Originarios Salteños, Unidad de Coordinación de Políticas para la Inclusión Social, Gobierno de la Provincia de Salta, Salta (inédito).

Centro de Investigación Innocenti (UNICEF) (2004): “Asegurar los derechos de los niños indígenas", Innocenti Digest, 11. Disponible en:

http://www.unicef-irc.org/aboutIRC.

Cohn C. (2002): "A experiência da infância e o aprendizado entre os Xikrin", en A.Lopes de Silva, A.Nunes y A. V. Macedo (eds.), Crianças indígenas: ensaios antropológicos, São Paulo, Global, pp. 117-149.

Colangelo, M. A. (2003): "La mirada antropológica sobre la infancia. Reflexiones y perspectivas de abordaje", en Serie Encuentros y Seminarios, Ministerio de Educación de la Nación, www.me.gov.ar/curriform/publica/oei_20031128/ ponencia colangelo.pdf.

Colangelo, M. A. (2004): “En busca de una 'infancia sana': la construcción médica del niño y del cuerpo infantil”, Actas en CD rom del Simposio "Miradas antropológicas sobre la niñez", VII Congreso Argentino de Antropología Social, Villa Giardino, Córdoba.

Confederación Mapuche Neuquina (1994): ;Marici weu! ;Diez veces estamos vivos... Diez veces venceremos!, Concepción del Uruguay, Entre Ríos, Ediciones Búsqueda de AYLLU.

Datachaco Portal de Noticias (2014): "Habría aparecido en México un menor qom chaqueño", Policiales. Disponible en: http://www.datachaco.com/noticias/view/35457. [Consulta: 1/10/2014].

De Sousa Santos, B. (2005): "A crítica da governação neoliberal: O Fórum Social Mundial como política e legalidade cosmopolita subalterna", Revista Crítica de Ciências Sociais, 72, pp.7-44.

De Sousa Santos, B. (2010): Descolonizar el saber, Reinventar el poder, Montevideo, Ediciones Trilce.

Enriz, N. y M. García Palacios (2008): “Deviniendo Kuña va'era”, en S. Hirsch (coord.), Mujeres indigenas, Buenos Aires, Biblos, pp. 205-230.

Falaschi, C., F. Sánchez y A. Szulc (2005): "Políticas indigenistas en Neuquén: Pasado y presente", en C. Briones, ed., Cartografias Argentinas. Políticas Indigenistas y formaciones provinciales de alteridad, Buenos Aires, Antropofagia, pp.179-221.

Fonseca, C. y A. Cardarello (1999): "Direitos dos mais e menos humanos", Horizontes Antropológicos, Porto Alegre, 5(10), pp. 104-112. 
Fonseca, C. y P. Schuch, (orgs.), (2009): Políticas de proteçao à infancia: um olhar antropológico, Porto Alegre, Editora da UFRGS.

Frankenberg, R., I. Robinson y A. Delahook. (2000): “Countering essentialism in behavioural social science: the example of 'the vulnerable child' ethnographically examinated", The Sociological Review, Oxford, 48 (5), pp.586-611.

Giberti, E. (1998): "Una historia de omisiones", en Perspectivas No 9, Isis Internacional, pp.3-8.

Godelier, M. (1998): "El Occidente, ¿espejo o espejismo de la evolución de la humanidad? Algunas reflexiones sobre el proceso de occidentalización del mundo y sus vínculos con la evolución de la antropología”, en L. Arizpe (ed.), Dimensiones culturales del cambio global, México, UNAM/CRIM, pp.92-114.

Guber, R. (2005): El salvaje metropolitano, Buenos Aires, Paidós.

Hecht, A.C. y M. García Palacios (2010): "Categorías étnicas en el entramado social. Un estudio con niños y niñas de un barrio indígena", Revista Latinoamericana en Ciencias Sociales, Niñez y Juventud, 8 (2), pp.981-993.

Jenks, Ch. (1996): Childhood, London and New York, Routledge.

Katz, C. (1996): "Introduction", Anthropology of Work Review, 17 (1 y 2), pp.3-8.

Kreimer, O. y V. Figueroa (2008): Los derechos de los pueblos indígenas explicados para todos y toda, Argentina, Fondo de Naciones Unidas para la Infancia.

Lazzari, A. (2011): "Presentación del debate: Reclamos, restituciones y repatriaciones de restos humanos indígenas: cuerpos muertos, identidades, cosmologías, políticas y justicia”, Corpus. Archivos virtuales de la alteridad americana, 1 (1), pp. 1-7.

Llobet, V. (2006): "Las políticas sociales para la infancia vulnerable. Algunas reflexiones desde la Psicología", Revista Latinoamericana de Ciencias Sociales, Niñez y Juventud, 4 (1), pp.3-27.

Lopes, J. S. (2006): "Sobre processos de "ambientalização" dos conflitos e sobre dilemas da participação", Horizontes antropológicos, 12 (25), pp.31-64.

Lenton, D. (2009): "Acuerdos y tensiones, compromiso y objetividad: el "aporte antropológico" en torno a un conflicto por territorio y recursos entre mapuches, gobiernos y capitales privados", Espacios de crítica y producción, 40, pp.4 - 12.

Lenton, D. y M. Lorenzetti (2005): "Neoindigenismo de necesidad y Urgencia: la inclusión de los Pueblos Indígenas en la agenda del estado neoasistencialista", en C. Briones (ed.), Cartografias Argentinas. Politicas Indigenistas y formaciones provinciales de alteridad, Buenos Aires, Antropofagia, pp.293- 325.

Marx, C. (2012 [1867]). El Capital. Libro I, México, Siglo XXI.

Merry, S. E. (2006): "Transnational Human Rights and Local Activism: Mapping the Middle", American Anthropologist, 108 (1), pp.38-51.

Messer, E. (1993): “Anthropology and Human Rights", Annual Review of Anthropology, 22, pp. 221-249.

Mombello, L. (2002): "Evolución de la política indigenista en Argentina en la década de los noventa", CLASPO, The University of Texas at Austin, Disponible en: http://lanic.utexas.edu/project/laoap/claspo/dt/0004.pdf.com [Consulta: 29 de abril de 2014]. 
Oszlak, O. (1978): "Formación del Estado en América Latina. Elementos teóricometodológicos para su estudio", Estudios Cedes, 1 (3), pp.5-44.

Página 12 (2009): Una campaña por los niños indígenas. Disponible en: http://www.pagina12.com.ar/diario/sociedad/3-131961-2009-09-18.

Picas Contreras, J. (2006): "Los límites de la solidaridad. Las ONG y el mercado de "bienes simbólicos", Gazeta de Antropología, 22, pp.1-23.

Rabello De Castro, L. (2012): "Children-Democracy and emancipation", Alternatives: Global, Local, Political, 37 (2), pp.165-177.

Ratier, H. (1988):"'Indios, gauchos y migrantes internos en la conformación de nuestro patrimonio social", Revista ÍNDICE para el Análisis de nuestro tiempo, segunda época, 1 (2), pp. 26-51.

Rodríguez, M. E. (2011): “"Casualidades" y "causalidades” de los procesos de patrimonialización en la provincia de Santa Cruz", Archivos virtuales de la alteridad americana, 1 (1), pp.1-7.

Schuch, P. (2009): Práticas de justiça. Antropologia dos modos de governo da infância e juventude no contexto pós-ECA, Porto Alegre, UFRGS Editora.

Szulc, A. (2004): "Mapuche se es también en la waria (ciudad). Disputas en torno a lo rural, lo urbano y lo indígena en la Argentina", Política y Sociedad, 41 (3), pp. 167-180.

Szulc, A. (2006): “Antropología y Niñez: de la omisión a las 'culturas infantiles"”, en Wilde, G. y P. Schamber (eds.), Cultura, comunidades y procesos contemporáneos, Buenos Aires, Editorial SB, Colección "Paradigma indicial".

Szulc, A. (2007): Encrucijadas Identitarias: Representaciones de y sobre niños mapuche del Neuquén, Tesis Doctoral, Buenos Aires, Facultad de Filosofía y Letras, UBA. m.i.

Szulc, A. (2013): "El "cuidado" de los niños/as mapuche en disputa. Una indagación antropológica sobre prácticas familiares, comunitarias y estatales en tensión”, $X$ Reunión de Antropología del Mercosur, Córdoba, Argentina.

Szulc, A. (2015): La niñez mapuche. Sentidos de pertenencia en tensión, Buenos Aires, Biblos.

Tamagno, L. (2009): "Saberes, ética y política. La restitución de restos humanos en el Museo de La Plata”, en L. Tamagno (ed.), Pueblos indigenas. Interculturalidad, colonialidad, política, Buenos Aires, Biblos, pp.105-113.

Tassinari, A. (2007): “Concepçoes indígenas de infância no Brasil”, Tellus 13 (7), pp. 11-25.

Taylor, S. y R. Bogdan (1998): Introducción a los métodos cualitativos de investigación, Barcelona, Paidós.

Thorne, B. (2004): "Editorial: theorizing age and other differences", Childhood, 11 (4), pp.403-408.

Tissera, M. (2014): Disputas en torno a la instalación del cuidado y protección de los niños y los cuidados parentales como una "problemática social", Tesis de Licenciatura, Universidad de Buenos Aires.

Turner, V. (1974): Dramas, Fields, and Metaphors, Ithaca, Cornell University Press. 
UNICEF (s/f.): Campañas. Disponible en: http://www.unicef.org/argentina/spanish/media_333.htm

UNICEF (2009): Campaña por los derechos de la niñez y adolescencia indígena. Disponible en: http://www.unicef.org/argentina/spanish/media_16006.htm

UNICEF (2014): Semana del Prematuro. Disponible en: http://semanadelprematuro.org.ar/.

Vianna, A. de Resende Barreto (2002): Limites da minoridade: tutela, familia e autoridades em julgamento. Tese de doutorado, PPGAS, Museu Nacional/UFRJ, Rio de Janeiro

Vinelli, C. (2006): "La comunicación global: el caso de una campaña de UNICEF", en S. Carli (ed.), La cuestión de la infancia: entre la escuela, la calle y el shopping, Buenos Aires, Paidós, pp.181-204.

Williams, R. (2001 [1973]): El campo y la ciudad, Buenos Aires, Paidós.

Wilson, R. (1997): “Human Rights, Culture and context: an Introduction”, en R. Wilson (ed.), Human Rights, Culture and context. Anthropological perspectives, London, Pluto Press. 